\title{
"IMPEACHMENT" E IMPEDIMENTO DO TITULAR DO PODER EXECUTIVO
}

\author{
SANSÃO JOSÉ LOUREIRO \\ Professor Assistente de Direito Constitucional na \\ Faculdade de Direito da Universidade Federal do \\ Paraná
}

1. Não importa, no momento, pesquisar a origem e a justificação da mais alta magistratura de uma Nação. Poderiamos simplificar a questão dizendo que a inegável supremacia atual do Poder Executivo tem fundamentos não só históricos, sociológicos, políticos, econômicos, militares, como, principalmente, psicológicos. A mística em torno do chefe; a esperança de que ele seja capaz de encontrar o caminho da felicidade do Estado, conseguindo satisfazer a classe política e o povo; a condução do Estado de maneira a colocá-lo em posição de manter a paz com os demais, dão ao Poder Executivo, mais através de idealização do que por realismo, uma especial conotação psico-social. Monarquia e República, parlamentarismo e presidencialismo revezam-se nas preferências como instrumentos de governo; eleiçồes diretas e indiretas, válidas ambas sob determinadas condições políticas, trazem à baila problemas de legitimidade democrática. Mas, qualquer que seja a situação, a chefia máxima do governo é a figura central, o interesse permanente da classe política e dos governados. $O$ panorama vai a tal ponto que se pode duvidar que um homem ou mulher, por melhor dotados que sejam, possam, sozinhos, desempenhar a árdua missão de titular do Poder Executivo. Daí, a importância das assessorias, com os consequentes problemas de desempenho, de pressões externas e internas, de participação, afinal as decisões do Executivo, que também transferem para essas assessorias as preocupações dos cidadãos.

Temos dito, em várias oportunidades, que a hipertrofia do Poder Executivo não diminui a validade do princípio da separação dos Poderes. Ao contrário, serve para sustentá-la. O fortalecimento do Executivo obriga os demais poderes constituídos a se transformarem, encontrando eles mesmos novas maneiras de participação na mecâ- 
nica do Estado. Assim, não concordamos com os cientistas políticos ou com os constitucionalistas que proclamam o fim da separação dos poderes como axioma de direito constitucional. A existência de crises é sintoma de que algo precisa ser modificado, o que não anula a tese em sí: é impossível a liberdade política sem a separação e a harmonia entre os poderes.

Resulta do exposto, que a crise do princípio da separação dos poderes, na atualidade, salienta a hipertrofia do Executivo, aumentando a importância do titular deste Poder. Condições várias o levarão para caminhos democráticos, autocráticos ou ditatoriais.

A medida que aumenta 0 número dos participantes nas eleições - quer um eleitorado relativamente pequeno e qualificado por uma ortodoxia ideológica, quer um eleitorado quantitativamente elevado e representando um número muito grande de opiniões políticas - aumenta a dificuldade da atuação do Poder Executivo. Como expressará, no exercício de suas funções, os anseios das forças políticas atuantes no momento? É a difícil arte de sustentação no poder, que não pode estar divorciada da sustentação do próprio Estado como ente soberano.

Não se pode, portanto, já que tratamos de condições humanas, deixar de considerar o problema do exercício da função executiva como o mais importante da atividade política, relembrando, mais uma vez, a nossa confiança no princípio da separação de poderes.

Se a cessação do exercício da função executiva por uma determinada pessoa pode ocorrer por morte (natural, acidental, violenta), por renúncia, por deposição, por ausência, pode também estar sujeita à condições de ordem constitucional, geralmente por autoria de crime contra a Lei Magna, remotamente, por incapacidade para governar, ou por impossibilidade física para o exercício da função. Dentro deste contexto, consideraremos apenas o "impeachment", pena política que tem como resultado a decretação da perda de mandato, e, o impedimento, declaração de um estado de fato que impede o titular de continuar à frente do Executivo, mantidos em seu favor direitos e prerrogativas que o protegem no campo moral e jurídico.

2. O "impeachment" no Direito Comparado. Tido como originário da Inglaterra, neste país, com exclusão do Rei ou da Rainha que "can do no wrong" a ele estão sujeitos todos os súditos do reino, pares ou comuns, altas autoridades ou simples cidadãos, militares ou civis, investidos ou não em funções oficiais" (Paulo Brossard, "O Impeachment", p. 23), podendo a Câmara dos Lordes, exercendo função judiciária, aplicar as mais variadas penas. 0 "impeachment", 
que não é aplicado na Inglaterra há quase dois séculos, tem, nesse país, a natureza mais penal do que política.

Inspirados na tradição britânica, os norte-americanos adołaram - instituto, desenvolvendo-o, entretanto, com características próprias: podendo ser aplicado a várias autoridades (Const. Americana, art. II, Sec. IV, "The President", the Vice President and all civil Officers of the United States, shall be removed from Office on Impeachment for, on Conviction of, Treason, Bribery, or other High Crimes and Misdemeanors") funcionando a Câmara como órgão de acusação e o Senado como órgão julgador (Art. 1, Secs. 1 e 3 da Const. Americana) indo a pena política até a destituição do cargo e a inabilitação para o exercício de função pública, sem prejuízo da ação da justiça comum se o fato constituir crime previsto em lei. Do "impeachment" propriamente dito são excluídos os militares e congressistas. No plano do Estado-membro, a Federação Americana contempla não só o "impeachment" do governador, decretado pelo Legislativo, como também a revogação (recall) do governador e de outros funcionários. Na informação de Ferguson and McHenry ("The American System of Government", 8. ${ }^{a}$ ed., p. 604)" cerca de um quarto dos Estados possuem legislação para destituição pelo "recall". Esta medida permite aos eleitores, através da assinatura de petições, requerer uma eleição especial para determinar se uma autoridade deve ser ou não substituida antes do término de seu mandato". Casos concretos exemplificam estas medidas na história constitucional norte-americana. Juízes, ministros, governadores sofreram "impeachment" ou "recall". Entretanto, a absolvição do Presidente Andrew Johnson, em 1868, marcou a última tentativa de "impeachment" do Executivo federal americano.

O instituto do "impeachment" pode ser encontrado em outros países, não importando a exemplificação exaustiva à finalidade deste artigo. O modelo inglês e o norte-americano foram mencionados porque inspiradores de nossa legislação a respeito do "impeachment", respectivamente no Império e na República.

3. Nossa Constituição Imperial estabelecia, no capítulo referente ao Poder Moderador que "A pessoa do Imperador é inviolável e sagrada; ele não está sujeito a responsabilidade alguma". (Art. 99). Dizia, no art. 133 que os ministros de Estado seriam responsáveis por traição; por peita, suborno ou concussão; por abuso do poder; pela falta de observância da lei; por obrarem contra a liberdade, segurança ou propriedade dos cidadãos e por qualquer dissipação dos bens públicos. Exigia a Constituição de 1824 uma lei para "especificar a natureza desses delitos", advertindo ainda que não 
salvava "aos ministros da responsabilidade a ordem do Imperador, vocal ou por escrito (art. 133)". A Câmara dos Deputados recebeu a incumbência da acusação contra os Ministros e Conselheiros de Estado, sendo do Senado do Império a competência exclusiva para "Conhecer da responsabilidade dos secretários e conselheiros de Estado (art. 47, § $2 .^{\circ}$ ).

A lei exigida pela constituição foi sancionada em 15 de outubro de 1827, tendo um caráter nitidamente penal, como se pode observar no exemplo: "Art. $1 .^{\circ}-$ Os ministros e secretários de Estado são responsáveis por traição: $\S 1 .^{\circ}$ - Atentando por tratados, convenções e ajustes, dentro ou fora do Império, ou por outros quaisquer atos de seu ofício, ou prevalecendo-se dele com dolo manifesto: $1 .^{\circ}$ - contra a forma estabelecida do governo; $2 .^{\circ}$ - contra o livre exercício dos poderes políticos reconhecidos pela Constituição do Império; $3 .^{\circ}$ - contra a Independência, integridade e defesa da nação; $4 .^{\circ}$ - contra a pessoa ou vida do Imperador, da Imperatriz ou de algum dos princípios ou princesas da imperial família. § $2 .^{\circ}-$ Maquinando a destruição da religião Católica A.postólica Romana. § $3 .^{\circ}$ - São aplicáveis aos delitos especificados neste artigo as penas seguintes: Máxima: morte natural; média: perda da confiança da nação e de todas as honras; inabilidade perpétua para ocupar empregos de confiança, e cinco anos de prisão; mínima: perda da confiança da nação, inabilidade perpétua, restrita ao emprego em que é julgado, e cinco anos de suspensão do exercício dos direitos políticos".

Seguindo o modelo norte-americano, todas as Constituições Republicanas Brasileiras estabeleceram a possibilidade de "impeachment" do Executivo. A primeira lei que definiu os crimes de responsabilidade do Presidente da República serviu de motivo para que - Mal. Deodoro, nosso primeiro Presidente, desse um golpe de Estado, na tentativa de livrar-se, pelo fechamento, de um Congresso incômodo. O Congresso recusou o veto de Deodoro à Lei que definia os crimes de responsabilidade do Presidente da República tornando definitivo o conflito entre Executivo e Legislativo. Abortado - golpe de Estado, a lei foi promulgada por Floriano.

Na República, a Câmara dos Deputados deixou de considerar pedidos de "impeachment", por não constituirem" objeto de deliberação", contra os Presidentes: Floriano, Campos Sales, Hermes da Fonseca e Getúlio Vargas (último período de governo). 
4. No plano constitucional brasileiro, a matéria é também regida pela Lei n. ${ }^{\circ}$ 1079, de 10 de abril de 1950. Esta lei, que "define os crimes de responsabilidade e regula o respectivo processo dejulgamento", quanto à eficácía, vigora na sua quase totalidade. Resta saber se, no caso concreto, sua aplicabilidade não entraria em conflito com os postulados implícitos de nossa legislação revolucionária. surgida após os acontecimentos de 1964.

De qualquer forma, a Constituição Brasileiro de 1967/Emenda 1 e a lei n. ${ }^{\circ} 1079$ dão ensejo a algumas observações.

a. Desenvolvendo os caminhos traçados pela Constituição de 1946, a Lei n. ${ }^{\circ} 1079$ é eficaz se confrontada com a Constituição atual, mantendo em sua quase totalidade a natureza e os objetivos do "impeachment".

b. A Constituição vigente no país acrescentou na espécie, esse detalhe: Art. 83, $\S 2 .^{\circ}$ - Se, decorrido o prazo de sessenta dias, 0 julgamento não estiver concluído, será arquivado o processo".

c. A lei faz a distinção nítida entre crimes comuns praticados pelo Executivo e crimes de responsabilidade, definindo, evidentemente, estes últimos. O confronto do art. 40 da C. F. ("Compete privativamente à Câmara dos Deputados: 1 - Declarar, por dois terços, de seus membros, a procedência de acusação contra o Presidente da República e os ministros de Estado;") com o art. 83 ("O Presidente, depois que a Câmara dos Deputados declarar procedente a acusação pelo voto de dois terços de seus membros, será submetido a julgamento perante o Supremo Tribunal Federal, nos crimes comuns, ou perante o Senado Federal, nos de responsabilidade") poderia levar à interpretação errônea, dada a natureza do "impeachment". Medida política ou político-penal? Exemplifiquemos. O Presidente da República comete um homicídio. A Câmara deve julgar procedente a acusação por dois terços de seus membros, e, em caso positivo, o Presidente ficará suspenso de suas funções, devendo ser julgado perante o Supremo Tribunal Federal. A Constituição não é expressa sobre a prisão em flagrante do Presidente, sobre quem apresenta a denúncia (o Procurador-Geral da República é agente de confiança do Executivo, por ele demissível "ad nutum"), sobre como deve agir o Poder Judiciário na necessidade de decreto de prisão preventiva, etc. A solução, entretanto, não é difícil, porque pode ser encontrada, por analogia, ou implicitamente, no procedimento, v.g. estatuído por várias constituições brasileiras no que diz respeito às imunidades parlamentares. Se houver condenação, a pena acessória de perda de função eletiva será decorrente da pena principal. 
Até aqui, nada de especial, porque o fato constituiu-se em crime diferente do crime de responsabilidade. Ora, no julgamento do crime de responsabilidade, em concorrendo dois terços de votos dos senadores "será proferida sentença condenatória, e a pena limitar-se-á à perda do cargo, com inabilitação para o exercício de função pública, sem prejuízo da ação da justiça ordinária" (C.F. art. 42, Parágrafo único). Aqui, um mesmo fato poderá dar origem a um "bis in idem" quando ele ensejar um julgamento político e um julgamento comum. A Câmara dos Deputados julga procedente a acusação contra um Presidente da República por infração do art. $8 .^{\circ}, 1$, da lei que define crimes de responsabilidade: "tentar mudar por violência a forma do governo da República"; o Senado condena o Presidente, na forma constitucional, à perda do cargo, "sem prejuízo da ação da justiça ordinária. ("Justiça ordinária" nos parece estar aí por "justiça diferente da justiça política"). Juízo político antecipado: perda do cargo. Juízo ordinário consequente: denúncia por infração à Lei de Segurança Nacional ao "tentar" mudar, por meio violento, a Constituição no todo ou em parte ou a forma de governo por ela adotada". Os delitos patrimoniais poderiam ensejar a mesma ordem de pensamento.

d. A lei garante ao acusado amplos meios de defesa.

e. A lei possui aspectos negativos, como nos exemplos: "A. Câmara dos Deputados elegerá uma comissão de três membros para acompanhar o julgamento. (Para que, se o julgamento deve ser público? Admitirá o Senado este acompanhamento?). "... e no caso de haver crime comum deliberará ainda sobre se o Presidente o deverá submeter à justiça ordinária, independentemente da ação de qualquer interessado" (Poderá esta disposição impedir a ação do Ministério Público?). "É permitido a qualquer cidadão denunciar o Presidente da República... por crime de responsabilidade... (A legitimação ativa, no caso, deveria ser deferida a um número maior de eleitores)...

f. Prevendo também os crimes de Governadores e Secretário de Estado nas Unidades Federadas, mereceu a seguinte crítica do Prof. Paulo Brossard de Souza Pinto ("O Impeachment" cit. p. 83): "invadiu competência local e regulou o instituto no âmbito dos Estados. Para tanto, seu relator na Comissão Mista das Leis Complementares invocou $\circ$ art. 5. $, \mathrm{XV}, \mathrm{a}$, da Constituição. A esse ponto de vista, que chegou a ser repelido quanto ao processo, não faltaram impugnações. Aqui, como em outros passos da elaboração legislativa, se fêz sentir a influência dos recentes arestos do Supremo Tribunal, que esterilizaram a competência dos Estados, enfaticamente assegurada 
pela Constituição... A tanto levam as premissas falsas. E o esquecimento da História do Brasil".

A Constituição do Estado do Paraná, no art. 49, estabelece: "O Governador será julgado: I - nos crimes comuns, pelo Tribunal de Justiça; nos crimes de responsabilidade, por um Tribunal Especial, composto de cinco deputados e cinco desembargadores, sob a presidência do Presidente do Tribunal de Justiça, que terá voto em caso de empate. Parágrafo único. Os reputados serão eleitos pela Assembléia Legislativa, mediante voto secreto; os desembargadores, sorteados pelo Tribunal de Justiça, dentre os seus membros efetivos". (Nosso ponto de vista é no sentido de que os deputados também devem ser sorteados).

5. Os crimes de responsabilidade dos Executivos Municipais estão previstos no Decreto-Lei n. ${ }^{\circ} 201$, de 27 de fevereiro de 1967. Por esta legislação separam-se os crimes que são julgados diretamente pelo Poder Judiciário, sem necessidade de licença da Câmara Municipal para processo e julgamento, podendo resultar aplicação de pena de reclusão ou de detenção, ficando estabelecido no art. $1 .^{\circ}, \S$ 2..$^{\circ}$ "A condenação definitiva em qualquer dos crimes definidos neste artigo acarreta a perda do cargo e a inabilitação, pelo prazo de cinco anos, para o exercício de cargo ou função pública, eletivo ou de nomeação, sem prejuízo da reparação civil do dano causado ao patrimônio público ou particular. Outros há que são considerados como político-administrativos, "sujeitos ao julgamento pela Câmara dos Vereadores e sancionadas com a cassação do mandato.

6. De difícil enquadramento constitucional, quanto à "impeachment", são alguns Executivos contemplados na Constituição Brasileira atual, os interventores, nomeados na forma constitucional ou com base em Ato Institucional, para os Estados-membros e para os Municípios. Ainda não se estabeleceu no Brasil uma definição precisa do Interventor federal ou estadual, daí surgindo dúvidas sobre a possibilidade de decreto de "impeachment" dessa espécie de Executivo, por nâo serem consideradas autoridades locais, impossibilitando aos legislativos a aplicação da punição política. Com relação aos interventores municipais, o Dec.-Lei n. ${ }^{\circ} 201$ pode deslindar, em parte, a questão.

Como resolver o problema quando os acusados forem Governadores do Distrito Federal, Prefeitos das Capitais dos Estados e dos Municípios considerados estâncias hidrominerais, Prefeitos dos Municípios declarados de interêsse da segurança nacional, Prefeitos 
nomeados pelos Governadores de Territórios, estes mesmos Governadores de Territórios?

Pedimos vênia para tratar do assunto deste ítem, pela sua novidade e importância, em artigo separado, adiantando, entretanto, a necessidade de uma clara e urgente definição constitucional.

7. O Vice-Presidente da República, pela natureza do cargo, e, ao contrário do que está na Constituição Americana, para escapar da punição puramente política expressa no "impeachment" basta deixar o exercício da Presidência, transitoriamente ocupada por ele,

O "impeachment" tem destinatário certo, dele estando, no momento, excluídos, o Vice-Presidente da República e os Vice-Governadores nos Estados-membros. O Dec. Lei n. ${ }^{\circ} 201$, entretanto, definiu a questão na área de Vice-Prefeitos: art. 3..$^{\circ}$ : "O Vice-Prefeito, ou quem vier a substituir o Prefeito, fica sujeito ao mesmo processo do substituído, ainda que tenha cessado a substituição".

8. Impedimento. Se, de um lado, consideramos com Ferguson e McHenry que o "impeachment" é a medida pela qual alguma autoridade governamental é removida do cargo depois de formal acusação e julgamento perante um corpo legislativo", medida esta de rara utilização, que só poderá permanecer na sociedade democrática mediante aperfeiçoamento, resta agora caracterizar o impedimento do Executivo.

O impedimento ocorre quando a doença ou outra causa imposibilitam o Executivo de exercer plenamente suas funções constitucionais. A divisão e exemplos de impedimentos podem dar margem a uma discussão maior do que o interesse do presente artigo comporta). Nos Estados Unidos, em várias oportunidades, o Executivo permaneceu praticamente acéfalo em decorrência do estado de saúde de seus titulares. Não sendo casos de "impeachment", a Constituição não oferecia o caminho para o reconhecimento do impedimento. Por questão de política ou de cortesia. o substituto eventual não assumia as rédeas do governo. A aprovação da $25 .^{a}$ Emenda modificou o panorama.

O Brasil registra história própria no campo dos impedimentos do Executivo, originados todos eles em motivos de saúde, com as consequências políticas as mais variadas. Prudente de Moraes, Rodrigues Alves, vários governadores de Estado-membro, até os mais recentes casos dos Presidentes Café Filho e Costa e Silva. A doença deste último ensejou a edição do Ato Institucional n. ${ }^{\circ} 12$, que con- 
tinha, enire outros, estes artigos: $10^{\circ}$ - "Enquanto durar o impedimento temporário do Presidente da República, Marechal Arthur da Costa e Silva, por motivo de saúde, as suas funções serão exercidas pelos Ministros da Marinha de Guerra, do Exército e da Aeronáutica Militar, nos termos dos Atos Institucionais e Complementares, bem como da Constituição de 24 de janeiro de 1967. 4. ${ }^{\circ}$ - Cessado o impedimento... reassumirá as suas funções em toda a sua plenitude". O Ato Institucional n. ${ }^{\circ} 16$, de 14 de outubro de 1969, depois de dizer no preâmbulo que o Presidente Costa e Silva havia sido acometido de "lamentável e grave enfermidade que o impossibilitava para o pleno exercício de suas funções, não obstante achar-se em estado de lucidez... manifestou desejo de que se promovesse a sua substiłuição no cargo" declarou vago o cargo de Presidente. E não foi só. Declarou vago o cargo de Vice Presidente da República.

O caso do Presidente Café Filho talvez seja o principal da história constitucional do Brasil a respeito de impedimento. (Para maiores detalhes, recomendamos aos interessados a leitura do parecer do Dr. João de Oliveira Filho, com o título de "Impedimento do Presidente da República e o Princípio da Separação dos Poderes", publicado na Revista dos Tribunais n. 269 , p. 76 e segs.; e "Os Grandes Julgamentos do Supremo Tribunal Federal", vol. III, p. 354 e segs. Min. Edgard Costa). Não podendo decretar o "impeachment" do Presidente Café Filho, por não poder enquadrá-lo na Lei n. ${ }^{\circ} 1079$, o Congresso Nacional decidiu considerar este Presidente "impedido", "impedido também seu substituto eventual, Dep. Carlos Luz, Presidente da Câmara dos Deputados. No dizer do líder Deputado Gustavo Capanema, Café Filho e Carlos Luz estavam "maierialmente impedidos de exercer o governo"; que o Congresso tinha que reconhecer a situação de fato "do levante em massa do Exército $\mathrm{Na}$ cional para impedir o exercício da Presidência da República pelo Presidente da Câmara dos Deputados". "Resta-nos reconhecer a necessidade da aplicação imediata do preceito constitucional que cuida do chamamento ao exercício de determinada autoridade substituta, sem reconhecer a existência ou a ilegalidade do poder, simplesmente the declare o impedimento". "Quando falamos em chamamento do Vice-Presidente do Senado Federal não vinculamos a essa a idéia de deposição do Presidente da Câmara. Longe disso! Muito bem poderá acontecer que pela ação do Vice-Presidente do Senado no exercício da Presidência venha a cessar o impedimento do Presidente da Câmara, que poderia, então, retornar às suas funções. O que pleireamos é o império absoluto e impessoal da constitucionalidade". (Grifamos). 
A verdade é que não temos completa solução legal para o problema do impedimento. Os debates travados no Congresso Nacional em torno do caso Café Filho e no Congresso Americano no encaminhamento da 25. ${ }^{a}$ Emenda demonstram cabalmente que no texto constitucional devem figurar com clareza dispositivos que capacitem - Poder Legislativo ao desempenho de mais esta importante missão.

Vale repetir que o presente trabalho teve como objetivo tratar apenas de alguns aspectos relativos ao "Impeachment" e impedimento de titular do Poder Executivo. O que não exclui, é evidente, o contido na constituição e nas leis com relação a outras autoridades. 